\title{
Criminal Case Game as Cyberspace: Why Online Gaming Becomes Potentially Immersive
}

\author{
Fatou Bintou Diatta* \\ Institute Superieur de Management des \\ Risques (ISMR) \\ Senegal \\ fatoubintou.diatta@gmail.com
}

\author{
Ghanesya Hari Murti \\ Language, Communication, and \\ Tourism \\ Politeknik Negeri Jember \\ Jember, Indonesia \\ ghanesya@polije.ac.id
}

\begin{abstract}
Online gaming today is not only seen as leisure activity for children but also for specific purposes for adults. Criminal case has a specific interest in the adult players to get along with the cyberspace. The game offers the players the opportunity to play a role as a detective who has to solve crime. The game is indeed not designed for kids due to its specific requirement to understand clear instructions inside the gameplay. This research, however, applies the concept of automodernity to establish the idea that criminal case has potential immersive experience for the game player, especially because of 'the free choices' features such as making avatar or the profile, buying coins, and competing with other players. The method used in this research is the interviews on pro players who have been playing more than 12 hours a day. The result shows the quality of autonomy for the players in making free choices. The choices they made on the game triggered for more competing desire toward other players thus buying items becomes their need. The other features such as designing avatar and making deduction are rather accessory on the game. The illusion of making free choices or autonomy for the players to enjoy in the cyberspace is the immersive experience they desire which they cannot have in the actual life. The actual and virtual realities become blur since they somehow connected to other competing players, they become friend in real life.
\end{abstract}

Keywords-online gaming, criminal case, automodernity, autonomy, immersive experience

\section{INTRODUCTION}

Online Gaming has become significant factor for the growing cyberspace community. Game as in online gaming spurs one's creativity and brings pleasure at the same time. Though, it is sometimes seen as individual or personal activity when playing, the world inside the game requires more people to engage within the game. This intrigues for more understanding whether the players can develop or improve human socialization skills and interaction with the cyberspace community like in the actual world.

Now playing is no longer just a means of physical activity. Playing activities can now be done just by sitting in front of a computer screen. Advances in technology help people to do activities without spending too much energy. However, whether this is the progress or decline of a civilization is still debated by experts.

Playing online games leads to high dependency. Research in the UK says playing online games can cause mental disorder [1]. Kimberly Young states that there is a need for special treatment to eliminate adolescent dependence on online games [2]. This treatment must be done carefully so that there is no rejection from the patient. The debate grows because the number of the players are not reducing but even more growing though the fact from the research says the other way round [3]. Thus, it requires more understanding on how the online gaming is attractive to some serious players. The selected game in this research is Criminal Case because it is integrated on the social media application Facebook which becomes significant variable for the game to be popular.

Web 2.0 is a technology product that can provide human needs, for example, the need for socializing where visitors interact in a virtual world or cyberspace. Thus cyberculture cannot be separated from cyberspace or the virtual world. Cyberspace according to David Bell itself is a global network of computers, connected through communication infrastructure, which facilitates the form of interaction between remote actors [4]. With advances in technology, humans can socialize easily in cyberspace. An example of the convenience provided by technology in socializing is social media Facebook. This social media makes it easy for humans to communicate remotely with friends, relatives, and colleagues which can be done quickly. Facebook also allows its users to find new friends.

Facebook is no longer known as a social media website, but also an entertainment medium. Facebook provides game entertainment services to users. One of the game applications offered by Facebook is Criminal Case. Criminal Case is a game on the Facebook social media service. The way to play Criminal Case is to find items that can be used as evidence to solve a murder case. The evidence is used to find the murderer [5]. At first glance, Criminal Case is like a game of hiding and seek between the player and the murderer. This indicates that hide-and-seek games can no longer be done in groups. With the help of technology, playing hide and seek can be done individually with a computer device. One of the names of a game of hide-and-seek that can be played on a computer is Criminal Case.

Uniquely, the Criminal Case game is not only played by young children, but also by adults. It is a great success fro the game to be the runner up of most popular game on Facebook in 2013[6], which most of the game player is adult and they play this game to relieve stress while working. Criminal Case players can modify the avatar costume that represents it. This 
research will explain the meaning of adults to the online game Criminal Case on Facebook. Thus, contradicting ideas from what the psychologist says about the mental disorder and the number of rising players requires for more detailed explanation which can be formulated in to the binary perspective of the mental addiction and personal deliberation. Moreover, how could the online game such as Criminal Case limits the dependency and the independency of the players? Those are the problem which requires more theoretical concept coming from cyberspace theory which covers the problem of modernity as the core issues. More concepts such digimodernism and postmodern perspective are included to help better analysis.

\section{BACKGROUND OF THE STUDY}

\section{A. Cyberspace and Automodernity}

The study of gaming culture does not rely only on readers to do this get a new approach to an increasingly technological and economic area power but more into the the various contested and transnational playing games community in that territory.

The appreciation of plurality in and of itself just will not do because it is arguably limited in both its rhetorical reach and pedagogical function. Concomitantly, our focus in this collection is equally on examining the continuities between, and interfaces among, as well as the co-evolution of game industries - cultures - communities within the region [7]. In contrast, these technological objects have an equal emphasis on joining together a high degree of mechanical automation with a greater personal taste autonomy. In fact, this unexpected and innovative combination of autonomy and automation can be read as the defining contradictions of contemporary life which is the automodernity [8]. Importantly, while from a postmodern perspective, modern automation represents a disadvantage from personal control, in contrast automodernity, automation instructs to individual autonomy

\section{B. Digimodornism}

Digimodernism, as well as a break in textuality, brings a new textual form, content, and value, new kinds of cultural meaning, structure, and use. Equally, while digimodernism has far-reaching philosophical implications with regard to such matters as the good, truth, meaning, representation, and time, they are not directly related to pseudo modernism [9] . Thus, it is more into how the technology in this case give the user the limit of the liberties they have inside the virtual community and the ones they are directed without they know. This is related to what they have been desiring is actually being controlled in such way.

\section{METHODS}

The method used by the author in this paper is a new ethnography. New ethnography', as a term, refers to forms of social and cultural inquiry that have taken seriously the charge that social sciences have depicted the people being studied, particularly disenfranchised groups, such as working-class youth or non-Western people, in ways that do not do justice to their sense of reality [10]. This study describes the concepts, then use them in a case analysis. With literature review data collection techniques, interviews via Facebook chat with 2 informants and observation. Interviews were conducted via chat to facilitate the running of this research. The observations were done by the researchers while they were becoming the online players in the Criminal Case game and interacting with other players. The literature review is obtained from e-books, and journals on the internet. The informants of the research have an account on Facebook, the citizens of Senegal, aged 26-28 years, have worked on the online game player Criminal Case on Facebook.

The following are the informants' data in this study: Simone Bougazelli Correa, female, 26 years old, is from Senegal. Work as staff at Fran Prix. Currently, Simone Fatima is domiciled in Paris. Simone has a Facebook account since 2015 and started using game apps on Facebook in 2015 as well. Khadimoul Khadim, male, 28 years old, also comes from Senegal. He is currently working as a staff at the World Food Program Dakar and has a Facebook account since 2010. He started using the game applications on Facebook in 2013.

Another characteristic feature of new ethnography, as well as phenomenology, is that it is particularly interested in modes of experiencing the world, such as emotions [11] [12], embodiment or the sacred [13] [14], which have often been neglected by rationalistically orientated modes of social scientific inquiry. As such, new ethnography usually challenges concepts - such as 'resistance' - that social research uses to categorize or label individuals. It argues that these labels do not reflect the lived realities of the people being studied but often render them supporting evidence for the scholar's theoretical or political frameworks or projects [15]. Thus, the first step is to gather the information from the informant then their respond is analyzed through cyberculture theory to explain the life world they experience.

\section{RESUlTS AND DisCUSSION}

This section presents three subtopics, the first is the background knowledge of Facebook and criminal case, second is the informants responds and analysis using the cyberculture theory

\section{A. Facebook and Criminal Case}

Facebook is a global social media site. This social networking site, launched in February 2004, was created by Mark Zuckerberg with his Harvard University roommates and classmates, Eduardo Saverin, Andrew McCollum, Dustin Moskovitz, and Chris Hughes. Initially, this website was only intended for Harvard students. Then this website developed to countries on the American continent, to all corners of the world.

Early emergence into the global market, Facebook only provides services about "status" and sharing photos of the owner's account. This status and photo can be commented on by other account owners who are friends with him. From there, Facebook has developed as a place for various activities, starting from a gathering place for a community (group), as a place to promote merchandise (online shop), to as a place of entertainment (online games).

In some cases, Facebook can bring together friends or family who haven't seen for a long time. Owners of Facebook accounts increase the number of friends they have with their respective goals. However, none of these friendships were "real friendships," this was what Alan Kirby called "electronic friendships". Humans only need a keyboard and a computer 
screen to be able to convey feelings, tell stories, or share photos with friends. There is no need for physical contact connecting them.

Since the beginning of 2013, Facebook has started developing its website by adding features that provide entertainment to its users, namely the online game feature. Many types of games are offered by Facebook for its users. The early appearance of this game was difficult to access in Indonesia because Indonesia's internet speed was not sufficient for Facebook's online game needs. However, this game continues to develop until finally, it is easy to access by Facebook account owners in Indonesia. Some of the types of games available on Facebook are Casino, Cards, Puzzle, Hidden objects, Adventure, and so on.

Hidden objects are a game to find the objects on the computer screen. The object is not easy to find. It takes carefulness from the players to find these objects. Criminal Case is a game that looks for hidden objects. This game is quite popular among Facebook users.

Games are a form of human activity. Playing, since childhood, is taught to children to form a good mentality, empathy, cooperation, fun, and to give them fantasy. In the play, humans are faced with the choice, rules, competition, and victory and defeat. As old as the advent of sport, games also played a role in it. Because it has rules and goals, the play makes people challenged to try and try to achieve these goals.

Millions of people in the world spend a lot of time, energy, and money playing a game, which is currently dominated by digital games (games). Many reasons underlie the reasons for playing the game. As a place of existence, looking for pleasure, and many also play to make money or economic motives. All run it in media technology which is constantly being updated to satisfy its users. Games are the result of technological developments, which are among the fastestgrowing. Every year, hundreds to thousands of games are created and millions of games are sold worldwide.

This Criminal Case tells the story of a detective who is looking for evidence of a murder case. Players will work with electronic players who will help us find these items if time is running out. Playing accounts can also be helped with "other" accounts to get free energy or solve cases. Criminal Case has been played by more than 10 million Facebook users. Those who play this game come from different countries, backgrounds, and ages. This game is accompanied by music such as detective music that makes users feel as if they feel how to be a real detective. The objective of the game is to find the murderer. The trick is to find items that can be used as evidence to catch the murderer. The game also has a story about how to autopsy a corpse or analyze evidence.

The game is not necessarily free, there are some things money has to buy. For example, purchasing food to speed up the increase in player energy, or buying cash and coins to get clothes, changing avatars, or getting lab results faster because it needs to pay in dollars.

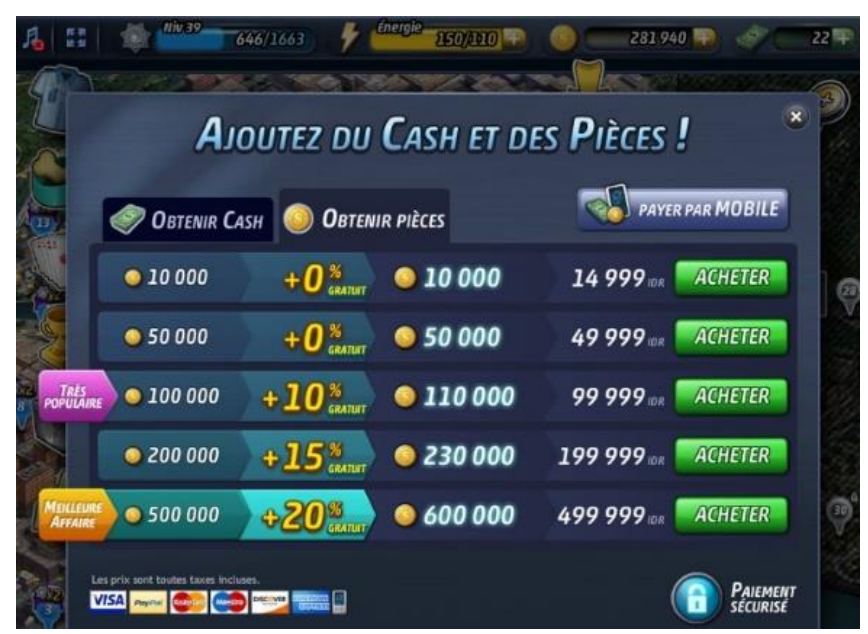

Fig. 1. Purchasing Cash and Coins to get items and speed up lab results.

The game is not necessarily free, there are some things money has to buy. For example, purchasing food to speed up the increase in player energy, or buying cash and coins to get clothes, changing avatars, or getting lab results faster because it needs to pay in dollars.

Moreover, Criminal Case players can also modify their appearance as detectives in this game. What can be modified is skin color, face shape, haircut, and you can even choose the desired gender. Gold coins are a means of payment used to modify appearance. These gold coins are earned every time a player completes a game session finding items in an image.

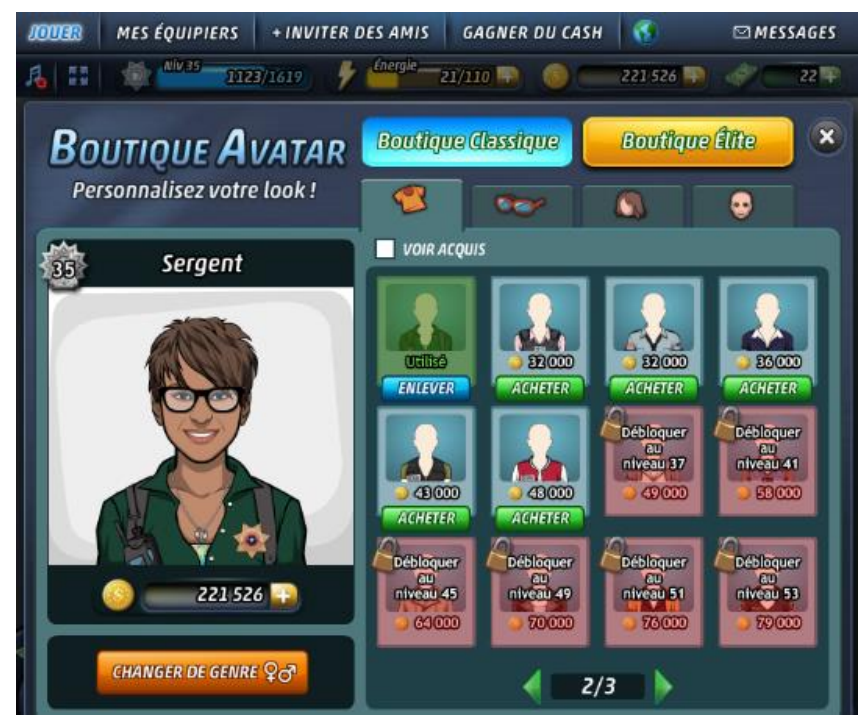

Fig. 2. The avatar shop where you can modify the player's appearance.

\section{B. Informant Responds and Analysis}

From the results of analysis made by researchers from the interview, the Criminal Case game creates an addiction for its players not in terms disorders but more into immersive experience they have during the game which gives the alternate reality they desire compared to the one they have in real life. The followings are their summarized comments of their experience during the game

\section{1) Simone Bougazelli Correa}

For Simone, playing Criminal Case is to get rid of boredom and help relax. Simone never plays at the office 
because he feels unprofessional. Usually, Simone plays this game online while on the bus or at home before going to bed to relieve fatigue. Simone never buys "food" to speed up his energy gain or buy cash. Because for Simone, playing online games does not require spending money, it is only to fill spare time. The free energy he gets for free which he uses to play Criminal Case. Simone has never interacted directly with other Criminal Case player partners. Simone also never made an appointment to play with her friends. Among all the types of games available on Facebook, Simone only plays Criminal Case and Candy Crush. For him, the online game Criminal Case can help increase concentration and help relax after a day of activities. With the story in the game, Simone doesn't feel bored and enjoys the game's storyline.

\section{2) Khadimoul Khadim}

Khadimoul Khadim did not feel addicted to the game Criminal Case. For Khadimoul Khadim, playing Criminal Case is to get rid of boredom while working besides that his office internet connection is very fast. On Facebook, besides playing Criminal Case, Khadimoul Khadim also plays another online game, namely Candy Crush. Khadimoul Khadim does not have a special time to play Criminal Case, but at least one day must open the game. Khadimoul Khadim never interacted directly with his playing partners. For Khadimoul Khadim playing Criminal Case is a place to learn new things such as new words, how to do lab analysis, how to work as a real detective. In Criminal Case, Khadimoul Khadim is level 116 but has never spent money on anything in the online game. There is no specific time playing Criminal Case, at least playing it once a day. For Khadimoul Khadim there are still many other important things to be fulfilled than buying it.

The online game Criminal Case is a game in cyberspace and a product of Digimodernism or technological developments. The relationship between players did not occur directly in the real world but the virtual world. Players are not physical playmate and can be represented virtually. Based on the results of interviews with informants, it was found that Criminal Case was considered only as a relief for momentary tired. Because the game is limited by energy, playing time is limited.

As explained earlier, Digimodernism has special characteristics. These characteristics appear in the online game Criminal Case, namely Onwardness, the online game maker Criminal Case continues to make innovations to satisfy its users. The higher the level the murder story gets the more diverse. Besides, to provide convenience to the wearer, purchasing "food" to accelerate energy gain can use phone credit (previously only credit cards were used). Furthermore, the characteristic of Haphazardness, in this case, Criminal Case as a digimodernism text is irregular and develops in all directions. It should also be realized that the online game Criminal Case has no strong social punishment so they are easily leaving the game when something happens. The online game Criminal Case also has the nature of eformulation and intermediation of textual roles, where players also have influence or role in the text. The fluid-bounded text feature also appears in this text, the Criminal Case player account can be manipulated according to the account owner's wishes. The digital era as it is today makes it easier for humans to change the information they have. This game also allows for the emergence of anonymous, multiple, and social authorship authors in cyberspace, as long as you have a Facebook account, all accounts can play this game.

One of the characteristics of Postmodernism is hyperreality where territory, a referential being, or a substance. It is the generation by models of a real without origin or reality: hyper-real [16]. The reality that appears in cyberspace, especially with the game Criminal Case, is when players choose the avatar they want and play seriously as if they are a real detective so that addiction grows stronger when playing the game, because they do not need to care about the feeling of other players since they do not know them in persons there. The back sound played in Criminal Case makes the players feel like they are working as a real detective and they are becoming to get more into the character when playing.

\section{CONCLUSION}

Criminal Case, which is a game application on the Facebook site, is cyberspace community. This game shows that human relationships no longer requires real life experiences because they enjoy to play their alternate version of them in cyber community with the electronic friendship rather than real friendship. Though they have time to release stress by talking to friend, the informants enjoy playing the online game more. Cyberspace has changed human habits, both culturally and socially. Facebook provides this service, to show that Facebook is no longer just a social media, but also a medium for gathering a more widening virtual community and they do not feel socially burdened when leaving the game because they can change their role of identity easily next time. However, the game installs the idea of competition to exploit every player desire of being the best on the game.

Criminal Case players who became informants in this study felt they were not fully independent or independent when playing though the game spoils them to have more self centered experience. They play Criminal Case just to get rid of tired after work. Even though they did not feel fully independent, the informant still feel they need to resume the game because the options that the game has to offer brings immersive experience for having so many options but very small punishment unlike what they have in real life. The time limitation given in the form of energy use in the game can indeed reduce the dependence of Criminal Case players but the players are still given freedom to negotiate and resist what the game is leading them into.

\section{REFERENCES}

[1] "Technology addiction: is it even possible? - BBC Bitesize." https://www.bbc.co.uk/bitesize/articles/zrnpxyc (accessed Nov. 20, 2020).

[2] K. Young, "Understanding online gaming addiction and treatment issues for adolescents," Am. J. Fam. Ther., 2009, doi: 10.1080/01926180902942191.

[3] "The History Of Gaming: An Evolving Community | TechCrunch." https://techcrunch.com/2015/10/31/the-history-of-gaming-anevolving-community/ (accessed Nov. 20, 2020).

[4] D. Bell, An Introduction to Cybercultures. 2006.

[5] "Criminal Case | Criminal Case Wiki | Fandom." https://criminalcasegame.fandom.com/wiki/Criminal_Case (accessed Nov. 20, 2020).

[6] "Founder Interview: Pretty Simple's Corentin Raux on building on Criminal Case's massive success." https://www.rudebaguette.com/en/2013/08/founder-interview-pretty- 
simples-corentin-raux-on-building-on-criminal-cases-massivesuccess/ (accessed Nov. 20, 2020).

[7] L. Hjorth, The Routledge Companion to Digital Ethnography. 2017.

[8] R. Samuels and R. Samuels, "The Automodern University: The Universal Individual and the Backlash against Social Discourse," in New Media, Cultural Studies, and Critical Theory after Postmodernism, 2009.

[9] C. Bonfiglioli, “ Book review: Alan Kirby, Digimodernism: How New Technologies Dismantle the Postmodern and Reconfigure Our Culture ," Discourse Commun., 2013, doi: 10.1177/1750481312472972c.

[10] J. Clifford, G. E. Marcus, and N. M. . of American Research (Santa Fe, Writing Culture: The Poetics and Politics of Ethnography: a
School of American Research Advanced Seminar. University of California Press, 1986.

[11] J. D. Douglas, J. M. Johnson, D. L. Altheide, and C. U. Press, Existential Sociology. Cambridge University Press, 1977.

[12] M. Merleau-Ponty and D. A. Landes, Phenomenology of perception. 2013.

[13] W. J. Morgan and A. Guilherme, "I and Thou: The educational lessons of Martin Buber's dialogue with the conflicts of his times," Educ. Philos. Theory, 2012, doi: 10.1111/j.1469-5812.2010.00681.x.

[14] E. Lévinas, "Ethics and infinity," Cross Curr., 1984.

[15] P. Saukko, Doing Research in Cultural Studies. 2011.

[16] J. Baudrillard, "Jean baudrillard. Simulacra and simulations," Jean Baudrillard, Sel. writings, 1998. 